\title{
Carolina Nabuco: uma lady em nossa literatura
}

\author{
Zahidé Lupinacci Muzart* \\ Universidade Federal de Santa Catarina
}

\begin{abstract}
Resumo: Neste artigo comento a obra de Carolina Nabuco detendo-me especialmente no livro Retrato dos Estados Unidos à luz da sua literatura.

Palavras-chave: Mulher e literatura. Carolina Nabuco. Literatura americana.
\end{abstract}

Entre as escritoras nascidas no século XIX e esquecidas pela historiografia literária, há ainda muitos nomes a serem estudados, divulgados, valorizados e, sobretudo, lidos. Um deles é o de uma

* É pesquisadora do CNPq. Possui graduaçâo em Letras Neolatinas pela Pontifícia Universidade Católica do Rio Grande do Sul (1961), Graduação em Música pela Escola de Artes da Universidade Federal do Rio Grande do Sul, doutorado em Letras pela Faculté des Lettres et Sciences Humaines, Université de Toulouse-Le Mirail (1970), pós-doutorado na Ecole des Hautes Etudes em Sciences Sociales, Paris (1983-1984). Tem experiência na área de Letras, com ênfase em Literatura Brasileira (História das escritoras no século XIX, Literatura e Mulher, feminismo e literatura, Simbolismo em Santa Catarina, Cruz e Sousa). Participa da coordenação do Instituto de Estudos de Gênero - IEG/UFSC e de duas editorias da Revista Estudos Feministas. Este artigo está programado para ser editado em livro, na UFC, há dois anos.

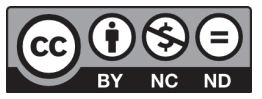

Esta obra está licenciada sob uma Licença Creative Commons. 
excelente escritora, Carolina Nabuco, que, apesar de reeditada, não tem merecido estudos mais avançados. Para o seu esquecimento náo concorreram fatores como etnia ou condiçóes sociais e econômicas. No grande grupo de escritoras que publicaram na primeira metade do século XX, seu nome não foi dos mais citados. Por muitos anos, ficou conhecida apenas como a biógrafa de seu pai.

Maria Carolina Nabuco de Araújo assinava somente Carolina Nabuco em todos os seus livros. Nasceu no Rio de Janeiro, a 9 de fevereiro de 1890, filha do jornalista e embaixador Joaquim Aurélio Nabuco de Araújo, escritor e senador do Império, e de D. Evelina Torres Ribeiro Nabuco. Joaquim Nabuco casou-se, no ano de 1889, com Evelina, filha do fazendeiro fluminense José Antônio Soares Ribeiro e neta do Barão de Itambi. Carolina veio ao mundo na década de noventa, no apogeu da Belle Époque, em uma família muito importante na vida nacional. Em consequência das constantes viagens do pai, sua educaçáo foi toda realizada na Europa e nos Estados Unidos, graças a professores particulares, como era usual nas famílias da alta burguesia. Quando volta ao Brasil, já é uma perfeita senhorinha da sociedade, mas com sólida formação linguística e literária, pois, tal como o próprio idioma, dominava as línguas inglesa e francesa. Era particularmente interessada pelos estudos de História e pelas biografias, para as quais provou ter talento especial em face do sucesso das que publicaria mais tarde. Afonso Arinos de Melo Franco, no Prefácio a A vida de Virgílio de Melo Franco, uma das biografias escritas por Carolina Nabuco, assim a descreve ao visitá-la em sua casa:

Carolina estava sentada na sala da frente, cheia de móveis e objetos antigos, vindos das duas famílias imperiais de que descende. Nas paredes havia gravuras de Piranesi, trazidas pelo pai, quando de sua missão em Roma, e uma bela fotografia dele, já grisalho e olímpico. Logo me impressionou a atitude habitual de Carolina que, em tantos anos de amizade, nunca vi mudar. É uma espécie de placidez senhoril, que impóe, desde logo, confiança e respeito. Se eu náo receasse as conotaçóes injustas, próprias 
destes nossos tempos vulgares, eu a chamaria atitude aristocrática. As impressôes de majestade, distância, orgulho, estão muito longe dela. Próximas se acham as de discrição, finura e bondosa dignidade. Exatamente aquilo que, naquele tempo, ainda se chamava educação (NABUCO, 1962, p. XIV).

Carolina Nabuco foi também crítica literária e ótima ficcionista. A admiração pelo pai foi fundamental em sua vida e somente depois de ter-lhe escrito a biografia, $A$ vida de Joaquim Nabuco, dedicou-se à sua própria ficção, tendo deixado, além do conhecido romance $A$ sucessora, um interessantíssimo livro de memórias, Oito décadas, o romance Chama e cinzas e um livro de contos - O ladrão de guarda-chuva e dez outras histórias. ${ }^{2}$ Escreveu ainda mais duas biografias, a de Santa Catarina de Siena e a de Virgílio de Melo Franco, e uma história da literatura americana que comentarei a seguir.

Sobre o seu mais famoso livro, a biografia de Joaquim Nabuco, assim escreve Medeiros e Albuquerque:

O livro de d. Carolina Nabuco sobre a vida de seu ilustre pai é talvez o mais perfeito desse gênero que se tem publicado entre nós. E' uma biografia, admiravelmente bem organizada. A autora soube tomar uma atitude, que dá a ilusão de inteira objetividade. Nunca ocupa o primeiro plano. Parece deixar sempre que os documentos falem por ela. E' sóbria, é correta, é elegantíssima na simplicidade de sua frase. Erigiu a seu pai o mais nobre monumento! (ALBUQUERQUE, 1942, p. 74).

A partir de suas memórias, podemos traçar-lhe o retrato, não íntimo, mas de suas ideias e de seu olhar sobre o mundo da época. Não só pelas memórias, mas pelo que escreveu seja de ficção, seja em

\footnotetext{
${ }^{2}$ A capa desta edição, realizada por Edith Gentil Pinheiro Guimarães, traz título diferente na capa e na folha de rosto: O ladräo de guarda-chuva e dez contos. Na folha de rosto, temos O ladrão de guarda-chuva e dez outras histórias (Rio de Janeiro: Record, 1969).
} 
outro gênero, como na interessante história da literatura americana que, curiosamente, se chama Retrato dos Estados Unidos à luz de sua literatura. Nesse livro, no qual transparece a todo momento a sua fina crítica, ela analisa nomes como Edgar Allan Poe, Henry David Thoreau, Benjamin Franklin, Ralph Emerson, James Lowell, Nathaniel Hawthorne, Herman Melville, Walt Whitman, Emily Dickinson, F. Scott Fitzgerald, Ezra Pound, T. S. Eliot, Ernest Hemingway, William Faulkner, Elizabeth Bishop e muitos outros. E ainda registra sua opinião sobre a literatura americana, apresentada em capítulos como 'A terra', 'Intolerância inicial', 'Primeiras consagraçôes literárias', 'Escravidão e guerra', 'Imagens do velho Sul', 'A evolução do conto', 'A língua americana 'e 'Poesia em novos moldes', entre outros. Um verdadeiro panorama da literatura norte-americana, com sua história, suas diversas tendências e movimentos literários, desde as origens até o século XX. O livro foi relançado pela Editora Nova Fronteira, em 2000, e permanece ainda atual, trazendo um panorama da literatura norte-americana.

Nabuco faz um apanhado geral, desde o século XVIII até as tendências da década de 60. Ressalta a importância dos colonizadores - os pilgrim fathers, ou pais peregrinos - que vieram da Inglaterra em 1620 a bordo do navio Mayflower, bem como o puritanismo que balizava e baliza até hoje - a sociedade local. Para confirmar a riqueza das ideias dos EUA, Carolina Nabuco disseca em vários capítulos fases da história da nação, como a escravidáo, a ameaça do socialismo e a sofisticaçấo dos anos $20 .^{3}$

Em 'A língua americana', por exemplo, descreve a evolução do idioma inglês desde o início do povoamento do território até o progresso imposto pelos tempos modernos. Observadora notável,comenta um traço do inglês falado pelos americanos, nos Estados Unidos, que é o sentido da velocidade:

\footnotetext{
${ }^{3}$ BUARQUE, Adriana. Escritora brasileira conta história da literatura norte-americana. Disponível em: http://www.ig.com.br/paginas/igler/destaques/nabuco/index.html. Acesso em: 29 set. 2008. 
O desejo de poupar tempo foi, e continua, fator constante e decisivo na evoluçáo da língua americana. A tendência para encurtar aparece nos substantivos, como movie, quickey; nos cortes em vocábulos compridos, como gas por gasoline, champ por champion, doc por doctor, ad por advertisement, pep por pepper; na concentraçáa de dois vocábulos num, como em to service, to model, to ready, to contact, to guest, to author, to partner, to orate. Todo o falar do americano sempre foi no sentido de velocidade [...] [e continua] a servir cada vez melhor o espírito do país e suas atividades incontáveis. [...] A linguagem falada nos Estados Unidos, além de possuir a incomparável riqueza do vocabulário que lhe veio da Inglaterra, e que seus escritores naturalmente aproveitam, é hoje mais concisa na forma, mais comprimida (à custa talvez de possíveis sutilezas), mas com novo vigor e maior velocidade (NABUCO, 1967, p. 79-82).

Os objetivos de Carolina Nabuco ao escrever este interessante livro foram expostos no prefácio:

O que almejei neste trabalho não foi tanto fazer crítica literária quanto - fundindo regióes, fatos históricos e livros - tentar um retrato da naçáo americana. A ideia me atraiu pela afeição à terra onde passei minha adolescência; pelo prazer que, através de uma longa vida, encontrei na leitura de seus principais escritores; pelo fato da lígua inglesa terme sido quase língua materna; mas principalmente pela confiança que me vem de que, por náo ser nem americana, nem de modo algum americanizada, posso estabelecer comparaçóes com outras terras e outras culturas, numa perspectiva como a que inspirou esta famosa sentença: "O estrangeiro é a posteridade". Dentro da imensa variedade de aspectos que táo vasto país oferece, procurei o que cada autor logrou comunicar da época ou da região a que pertenceu; o que cada um deles pôs em sua obra de mais tipicamente, ou de mais altamente americano; e finalmente a relação que se estabeleceu entre leitores e autores (NABUCO, 1967, p. xi). 
Retrato dos Estados Unidos à luz da sua literatura, muito bem fundamentado, revela uma excelente leitora a par de uma fina crítica. Mas é uma história da literatura muito pessoal, pois, a todo momento, Carolina Nabuco deixa transparecer a sua opiniáo acerca do autor analisado, do livro lido e dos preconceitos vislumbrados. De leitura agradável, é um dos primeiros livros de história da literatura americana publicados no Brasil. Em pesquisa, antes deste livro, só encontramos a Pequena História da Literatura Norte-americana, de autoria de Breno Silveira, de 1943, a História da Literatura Norte-americana, de autoria de Thomas H. Dickinson, de 1948, e Literatura americana no século XX, de Willard Thorp, de 1965.

O livro foi escrito com muita simpatia da autora pelo país onde passou sua juventude e do qual sempre guardou as melhores lembranças. Um livro escrito com afeto! Como afirma no Prefácio, buscou "dentro da imensa variedade de aspectos que táo vasto país oferece, [...] o que cada autor logrou comunicar da época ou da regiáo a que pertenceu; o que cada um deles pôs em sua obra de mais tipicamente, ou de mais altamente americano; e finalmente a relação que se estabeleceu entre leitores e autores" (NABUCO, 1967, p. XI).

Chamou-me a atençấo, porém, a importância conferida por Carolina, et pour cause, à literatura realizada por cidadãos negros. Inicia comentando o famoso romance abolicionista A cabana do pai Tomás $s^{4} \mathrm{e}$, em outro capítulo, ao final do livro, dá ainda um maior destaque ao assunto, quando escreve sobre a literatura contemporânea.

Do Prefácio, destaco ainda alguns comentários da escritora que podem mostrar a maneira como concebeu uma história da literatura, bem antes dos chamados Estudos Culturais. Como afirma, seu estudo da literatura americana "não poderia ser senão o reflexo de uma sensibilidade pessoal”. Acentuo, com um excelente resultado, um livro inteligente e bem escrito que se lê quase como uma ficção:

\footnotetext{
${ }^{4}$ Famoso romance de Harriet [Elizabeth] Beecher Stowe (1811- 1896), escritora americana, abolicionista, autora de mais de dez livros. Com o título original de Uncle Tom's cabin (entre nós, A cabana do Pai Tomás), foi primeiramente publicado de forma serial, entre 1851 e 1852.
} 
A romancista Harriet Beecher Stowe seria autora secundária em qualquer terra se certos personagens seus, como o velho negro Tomás e a corajosa escrava Elisa, não houvessem empolgado o público, e dado a seu Uncle Tom's cabin um destino fora de proporção com o talento real da autora. Foram eles, Tom e Elisa, que ganharam em grande parte a libertação de sua raça, através da obra mais divulgada do século, notável exemplo de como o eco pode superar a voz. Tampouco foi somente o talento de Hawthorne, sem dúvida apreciável, que lhe abriu um nicho definitivo entre as obras inconfundivelmente americanas. Sem sua obra-mestra, The scarlet letter, a letra que se queimava a fogo no peito da mulher adúltera não se teria constituído em símbolo - símbolo do fundo granítico dos puritanos sobre o qual se lançaram as bases da civilização americana. Ideado assim, este meu estudo da literatura americana náo poderia ser senáo o reflexo de uma sensibilidade pessoal. Se o retrato dos Estados Unidos que resultou dele não for julgado fiel, posso apenas alegar que é apresentado sem didática nem polêmica - o quadro que vejo, e que náo me atrevo a impor.(NABUCO, Carolina, 1973, p. xii)

E traz ainda, entre muitos outros, um capítulo dos mais interessantes sobre a poesia de Walt Whitman e de Emily Dickinson, intitulado 'Farol e lâmpada', sendo o farol, Whitman, e a lâmpada, Emily. Carolina Nabuco foi uma crítica competente com sólida formação literária e linguística, o que lhe permitiu escrever este livro do qual tentamos dar apenas uma ideia.

Carolina Nabuco estreou em 1929 com o livro $A$ vida de Joaquim Nabuco, que lhe valeu o prêmio de erudição da Academia Brasileira de Letras naquele ano. O êxito do livro, no Brasil, faria com que, em 1944, fosse traduzido para o espanhol e para o inglês. Para o espanhol, desimcumbiuse o embaixador dominicano Gilberto Sanchez Lustrino, tendo o livro sido publicado na Argentina. O tradutor para a língua inglesa foi o professor Ronald Hilton, da Universidade de Stanford, que o divulgou em seguida. Sobre o que chamava "seu livro" - a biografia de Joaquim Nabuco - declara o seguinte: 
Após aparecer meu livro sobre meu Pai, todos esperavam que eu continuasse a escrever. Nem eu queria outra coisa, embora visse bem as dificuldades. $\mathrm{O}$ assunto de meu Pai, para uma biografia, como que me havia caído do céu. Tive a felicidade de poder dedicar minha pena a uma figura rara, a um homem em cuja vida e em cuja ação nada havia que criticar ou justificar, e cujo talento me oferecia a colaboraçáo de trechos falados ou escritos, bastantes para fazer a grandeza do volume. Em outro assunto, se eu continuasse a escrever, teria que fazer coisa totalmente minha, sacar tudo do meu pensamento, da minha experiência, e, sobretudo, de qualquer dom criador que porventura houvesse em mim. (NABUCO, 1973, p. 110-111).

Afirma o crítico Hermenegildo de Sá Cavalcanti que "a biografia de seu pai, trabalho excelente, deveria ser adotado nas universidades e escolas, como adendo a melhor entendimento do autor de Um estadista do Império". $5 \mathrm{Na}$ mesma época, outra crítica literária, Lúcia Miguel Pereira, também lança biografia que se tornou um marco nos estudos sobre o autor, tendo publicado, em 1936, a primeira biografia intelectual de Machado de Assis e, mais tarde, a de Gonçalves Dias. Do mesmo modo, Carolina Nabuco especializou-se em biografias baseadas todas em criteriosa pesquisa.

Quando deixou a sombra de seu Pai, Carolina volta-se para a ficção:

Eu tinha um projeto de conto para o qual já escolhera título, "O retrato da primeira mulher". Seria uma espécie de diálogo entre uma esposa morta e aquela que lhe sucedeu. Cuidei de aproveitar e estender esse esboço, a fim de transformá-lo em romance. Acrescentei pormenores e episódios que pudessem dar mais vida às figuras principais e firmar o contraste entre as duas esposas - uma viva, outra morta.(NABUCO, 1973, p. 111).

\footnotetext{
${ }^{5}$ Hermenegildo de Sá Cavalcanti. A escritora Carolina Nabuco. "Orelha" do livro $O$ ladrão de guarda-chuva e dez contos (1969).
} 
Este projeto de conto transformou-se no romance A sucessora, publicado em 1934, um romance de cunho social e psicológico no qual, segundo Nelly Novaes Coelho,

[...] se mesclam atitudes, tendências ou ideais contrastantes que expressam bem o processo de modernização no Brasil da década de 1930, processo em que se defrontam os valores aristocratizantes da sociedade tradicional em declínio (a dos grandes proprietários de terra e suas legióes de trabalhadores-escravos) e da sociedade moderna em ascensão (a dos industriais e alto comércio, construída principalmente pelos imigrantes que passam a ser os novos ricos). Essas duas classes - a da aristocracia rural brasileira e a dos novos ricos urbanos - estáo representadas no romance por Roberto (descendente de imigrantes e novo rico), casado em segundas núpcias com Mariana (descendente da aristocracia rural empobrecida) (COELHO, 2002, p. 180).

O romance, segundo a autora, teve alguma procura, mas só alcançou real sucesso com a publicação de Rebecca, da escritora inglesa Daphne du Maurier, publicado em 1938, texto que deu origem ao filme de Hitchcock. A sucessora, em $5^{\text {a }}$ edição, traduzido para o espanhol e lançado no Chile, foi também editado em Portugal. Esse romance deu motivo a debate jornalístico, segundo Francisco de Assis Barbosa, quando a autora acusou de plágio a escritora inglesa que teria copiado não somente o enredo, como situações e diálogos de $A$ sucessora. Em artigo no Correio da Manhá, do Rio de Janeiro, e depois reunido ao volume Jornal de Critica, $1^{\text {a }}$ série, o crítico Álvaro Lins fez um sério estudo comparativo entre os dois romances, para concluir que se trata realmente de plágio $^{6}$ (LINS, 1941, p. 233-242).

\footnotetext{
${ }^{6}$ Estudei essa questão um pouco mais detidamente em À sombra da outra: a segunda mulher na literatura. In: DUARTE, Constância Lima; DUARTE, Eduardo de Assis; BEZERRA, Kátia da Costa (org). Gênero e representação na Literatura Brasileira. Belo Horizonte: Pós-Graduação em Letras, UFMG, 2002, p. 131-139.
} 
Mas a carreira de Carolina Nabuco não ficou restrita ao romance A sucessora, pois escreveu muito mais.

Gabriela Mistral escreve a propósito da autora de Chama e cinza:

Pocas veces me acarreó tanta alegria un escritor no metafórico ni lírico. Me parece que usted sea el novelista por excelência que hace solamente lo suyo sin recurrir a los géneros colaterales, para dar a un texto más valor o volverlo más convincente. Como usted, igualmente permeado de experiencia humana e igualmente limpio de recursos extraños, escribía sus novelas don Miguel de Unamuno, el español [...]. ${ }^{7}$

Seu maior talento talvez esteja no memorialismo, pois Oito décadas retrata maravilhosamente toda uma época. Muito bem escrito, é narrativa que deixa o leitor cativo, tal como se fosse uma obra de ficção. Neste livro, podemos acompanhar o desenrolar de seu tempo, de 1890 a 1970. Nele, encontram-se desde a vilegiatura do Imperador, em férias na cidade imperial de Petrópolis, até as viagens de Carolina aos Estados Unidos e à Europa.

O livro traz também lembranças da infância, de sua aprendizagem da leitura da língua francesa, ensinada por sua mãe, e de sua paixão pelos livros:

Aos cinco anos começou a deliciosa aventura de estudar com minha mãe. Ganhei uma carteira de colegial para meu tamanho, mas em cujo banco cabíamos as duas. Lembro-me (como se fosse hoje) da emoção que me assaltou no dia em que, tendo mais ou menos aprendido o alfabeto, eu descobri subitamente como se fazia a fusão das letras e exclamei exultante: - Ah! É assim? Então eu sei ler! Eu tinha verdadeira avidez de aprender tudo o que me quisessem ensinar. Minha mãe familiarizou-me cedo com o francês, que era para ela uma segunda língua materna.

\footnotetext{
${ }^{7}$ Apud Hermenegildo de Sá Cavalcanti. A escritora Carolina Nabuco. Gabriela Mistral, na orelha do livro O ladrão de guarda-chuva e dez contos (1969).
}

80 
Abriu-se com isso, para mim, o acesso à delícia dos livros da condessa de Ségur, hoje quase todos traduzidos, mas que naquele tempo só existiam nas ediçóes de capa de percalina vermelha da série da Bibliothèque Rose. As lições de mamãe corroboravam minha ansiedade em entender as histórias do livro, que eu manuseava com delícia antecipada aplicando-me em adivinhar o sentido (NABUCO, 2000, p. 14).

Mesmo salientando o talento da escritora como memorialista, também na ficção, na arte do conto particularmente, é preciso destacar a envolvência dos que compóem $O$ ladrão de guarda-chuva. A narradora vai pintando os caracteres por meio de pequenos e delicados traços. No conto intitulado $O$ viúvo, temos um viajante obcecado pelo amor à mulher morta. Aparentemente muito simples, o leitor mergulha na paixão do viúvo pela falecida até o surpreendente desfecho, quando a personagem fica conhecendo a verdade sobre a esposa morta, ou seja, o adultério em seu passado. Em O ladrão de guarda-chuva, conto que dá o nome à coletânea, temos outro enredo de grande simplicidade e contraste entre as açóes das personagens. A personagem principal é pobre e muito honesta. Apesar disso, rouba um guarda-chuva para proteger-se da chuva pelo medo das doenças de pulmão. A partir desse incidente, desenvolve-se o conto, com a introdução de outras personagens, com a descoberta do ladrão. $\mathrm{O}$ núcleo dos contos é sempre um pequeno fato, ideia, intençáo de uma personagem, originando-se daí então a narrativa e chegando ao clímax pela descoberta de algo novo.

Os temas na ficção curta de Carolina Nabuco lembraram-me o grande contista americano O. Henry, ${ }^{8}$ especialista em narrativas sobre a vida urbana, com especial foco nas virtudes e mesquinharias da classe média. Chamado de o Maupassant americano, foi muito lido no Brasil nos anos 50. Em seu Retrato dos Estados Unidos à luz de sua literatura, a escritora não dedicou muitas páginas a $\mathrm{O}$. Henry, embora, na análise que fez de Poe como contista e sua influência na técnica do conto, tenha ${ }^{8}$ O. Henry (1862-1910) era o pseudônimo usado por William Sydney Porter, um dos
maiores contistas americanos do século e um dos autores mais populares do seu tempo. 
inserido um comentário em relação a ele, demonstrando sua leitura: "O padráo estabelecido por Poe distinguiria durante muitas dezenas de anos a arte de que O. Henry nos Estados Unidos e Guy de Maupassant, na França, foram com ele os mais altos expoentes" (NABUCO, 1967, p. 35-40).

No livro citado acima, Carolina Nabuco debruçou-se sobre os contos de Edgar Allan Poe, que analisa a fundo, destacando a técnica e a originalidade que tiveram notória influência sobre Guy de Maupassant:

Enquanto em Poe a arte de criar expectativa, com interesse que não se abate é inexcedível e a originalidade constante, sua imaginação espalha-se à vontade na colheita dos sons, das cores, dos movimentos e dos cenários, criando o que hoje se chama atmosfera (NABUCO, 1967, p. 37).

Atmosfera é o que encontramos nos contos da própria Carolina Nabuco. A escritora cria o ambiente do conto com pequenas descriçóes, cria o enredo e chega, não diria a um suspense, mas à surpresa final. $\mathrm{O}$ conto $\mathrm{O}$ quadro da exposiçáo foi um dos que associei a $\mathrm{O}$. Henry - escreveu deliciosos contos em que o tema é o sacrifício que algumas personagens fazem por amor. Neste conto de Carolina há também a mesma temática: a renúncia da pintora em benefício de seu velho mestre, ato motivado por amor, respeito e devoção.

O segundo romance de Carolina Nabuco, Chama e cinzas, é menos impactante do que $A$ sucessora, mas ainda se sente, em cada pormenor, a intençáo de explorar profundidades da alma humana. $\mathrm{O}$ enredo se desenvolve em torno de quatro meninas sem mãe que vivem com o pai, Álvaro, um jogador inveterado sempre dando golpes, pedindo dinheiro emprestado aos amigos e conhecidos, permanecendo sempre endividado. É a mesma escritora a surpreender os movimentos íntimos de Rabelo, o triste processo psicológico do definhamento moral de Álvaro; enfim, todo o quadro de desejos sentimentais das meninas que figuram no romance. Das quatro filhas de Álvaro, uma, Nica, apresenta personalidade mais forte e acaba se tornando a grande personagem do 
livro. Apaixona-se por um rapaz que, aparentemente, corresponde a seus sentimentos, mas que, ao conhecer Yolanda, a mais bela das irmãs, se enamora dela e com ela se casa. Desta desilusão a personagem principal se reerguerá, continuará a vida cotidiana e, mais tarde, aceita o pedido de casamento de um grande amigo da família, um rico banqueiro, passando a viver em grande luxo até a morte do marido. $\mathrm{O}$ romance se ocupa da realidade de uma família à qual cedo faltou a mãe, substituída pelo pai, um pai alegre e simpático, mas que não sabia impor-se pela sua conduta, procurando sempre meios escusos de ganhar dinheiro. Estranhamente, esse pai meio desonesto e trambiqueiro conseguia manter alguns valores que o distinguiam: era um bom pai nas questôes afetivas. Recebia muito bem em sua casa e tinha muitos amigos, pois a simpatia era sua qualidade dominante.

Assim como Álvaro, há outras personagens dignas de análise por suas características psicológicas. O romance é dividido em duas partes: 'A Casa de Álvaro' e 'A Casa de Rabelo'. Na primeira, a narradora conta como viviam as filhas de Álvaro e os problemas financeiros da família, além da amizade do banqueiro Rabelo, que ampara o pai em suas crises de dinheiro. Já 'A Casa de Rabelo' mostrará a vida de Nica depois do casamento, a vida de luxo na alta roda carioca, os negócios do banqueiro e a morte deste, deixando-a sozinha a repensar seus valores, a solidão e as mudanças:

Sentia-se realmente desligada do mundo, e de tudo a que a inimiga ainda dava importância, e a que ela já dera muita também. Repudiava agora aquilo a que antes dava valor. Dessa vida que ardera e já passara, não via mais senão as cinzas, que restavam do fulgor, e que se estendiam diante dela, sem nenhum traçado, submergindo o que fora seu universo. Mas via, pela janela, que o dia estava claro e bonito... (NABUCO, 1947, p. 281).

Sobre a ficção de Carolina Nabuco, afirma Temístocles Linhares: 
A verdade é que esses livros denunciavam uma experiência do real pouco comum nas mulheres escritoras, inscrevendo-se assim entre as coisas boas que produzimos nesse domínio fenomenológico por excelência e que nos permite fixar alguns aspectos de nossa vida social e de personagens que nela se movimentam, numa apreensão bastante rica de nossos costumes e convençôes, de denúncia e de renúncia, de exploração e de adaptação a que estivemos sujeitos na primeira metade deste século. O seu maior mérito, a nosso ver, foi insistir sobre certas posições que nos obrigavam a voltar-nos para nós mesmos em alguma coisa de essencial para o nosso funcionamento social (LINHARES, 1987, p. 442).

A escritora ainda publica um livro de culinária muito bem fundamentado com noçôes de serviço à mesa e explicação de termos estrangeiros, sobretudo os franceses. O livro não é um livro comum de receitas, mas um interessante livro de memórias em que aprendemos muito sobre a belle-époque, a vida com o embaixador Nabuco e, sobretudo, a comida como cultura. ${ }^{9}$ Entremeando às receitas observaçóes e lembranças da vida em família e de suas viagens, a autora concilia a utilidade de um guia gastronômico às virtudes de uma obra literária.

Carolina Nabuco mostra em sua obra ficcional que foi uma grande leitora e uma estudiosa da arte literária, tendo realizado "uma obra que é um significativo reflexo do século passado, marcado por transformaçóes da herança tradicional" (COELHO, 2002, p. 180). Mas sua obra é marcada nitidamente como obra de memória. Iniciando-se pela biografia de seu pai, continua nas de Santa Catarina de Sena e a de Virgílio de Melo Franco, culminando com suas próprias e saborosas memórias que podem rivalizar com as excelentes de Pedro Nava. No entanto, apesar disso, ou talvez por essa razão, a de ser uma séria pesquisadora, conseguiu escapar do gueto da literatura feminina, escrevendo com liberdade e originalidade e erigindo as tramas psicológicas para a sua ficção, sendo reeditada até os dias de hoje.

\footnotetext{
${ }^{9}$ Meu livro de cozinha. 2. ed. Rio de Janeiro: Nova Fronteira, 2002. 84
} 


\section{OBRA}

\section{Biografias}

A vida de Joaquim Nabuco. 1. ${ }^{\mathrm{a}}$ e 2.a ed. São Paulo: Editora Nacional, 1929.

Santa Catarina de Sena: sua ação e seu ambiente. Rio de Janeiro: José Olympio, 1957.

A vida de Virgílio de Melo Franco. Rio de Janeiro: José Olympio, 1962.

Oito décadas. Memórias. Rio de Janeiro: José Olympio, 1973.

\section{Romances}

A Sucessora. São Paulo: Companhia Editora Nacional, 1934.

Chama e cinzas. Rio de Janeiro: José Olympio, 1947. Prêmio de Romance de 1947 da Academia Brasileira de Letras

\section{Contos}

O ladrão de guarda-chuva e dez outras histórias. Rio de Janeiro: Record, 1969.

\section{Viagem}

Visão dos Estados Unidos. Rio de Janeiro: Agir, 1953.

\section{Conferência}

Conferências sobre Nabuco. Recife: Imprensa Oficial, 1936. 


\section{Outros}

Retrato dos Estados Unidos à luz da sua literatura. (História Literária). Rio de Janeiro: José Olympio, 1967.

Joaquim Nabuco. (Literatura infantojuvenil). São Paulo: Melhoramentos, 1949; 2.ed., idem, 1955: 3. ed. idem, 1967. Série Grandes Brasileiros.

Catecismo historiado (Doutrina cristã para a primeira comunhão). Rio de Janeiro: José Olympio, [1940]; 2. ed., idem, 1945; 3. ed., idem, 1948; 4. ed., São Paulo: Melhoramentos, 1957.

Meu livro de cozinha. 2. ed. Rio de Janeiro: Nova Fronteira, 2002.

[Texto recebido em abril de 2013 para compor a corrente edição especial]

\section{Referências}

ALBUQUERQUE, José Joaquim C. da Costa Medeiros e. A vida de Joaquim Nabuco. In: $A$ Manhã, v. II, n. 5. Autores e Livros (suplemento literário). Rio de Janeiro, 8 de fevereiro de 1942. p. 74.

CAVALCANTI, Hermenegildo de Sá. A escritora Carolina Nabuco. (Orelhas) In: NABUCO, Carolina. O ladrão de guarda-chuva e dez outras histórias. Rio de Janeiro: Record, 1969.

COELHO, Nelly Novaes. Dicionário crítico de escritoras brasileiras. São Paulo: Escrituras, 2002, p. 180.

COUTINHO, Afrânio \& SOUSA, J. Galante de. Enciclopédia de literatura brasileira. v. 2. Rio de Janeiro: MEC, 1990.

DICKINSON, Thomas H. História da Literatura Norte-americana. São Paulo: Instituto Progresso Editorial, 1948. 
HOLLANDA, Heloísa Buarque de \& ARAÚJO, Lúcia Nascimento. Ensaistas brasileiras. Rio de Janeiro: Rocco, 1993, p. 75.

LACERDA, Lílian. Álbum de leitura. Memórias de vida, história de leitoras. São Paulo: UNESP, 2003, p. 124-128.

LINHARES, Temístocles. História crítica do romance brasileiro (17281981). Belo Horizonte: Itatiaia / São Paulo: EDUSP, 1987.

LINS, Álvaro. Rebecca, um plágio. In: LINS, Álvaro. Jornal de crítica. Rio de Janeiro: José Olympio, 1941, Primeira série, p. 233-242.

MENEZES, Raimundo de. Dicionário literário brasileiro. 2.ed. Rio de Janeiro: Livros Técnicos e Científicos, 1978, p. 474.

MISTRAL, Gabriela. Recado para Dona Carolina Nabuco. Texto na contracapa. In: NABUCO, Carolina. Chama e cinzas. Rio de Janeiro: José Olympio, 1947.

MUZART, Zahidé Lupinacci. Carolina Nabuco. Escritoras brasileiras do século XIX. v. III. Florianópolis: Mulheres, 2009, p. 209-246.

OLIVEIRA, Américo L. de \& VIANA, Mario G. Dicionário mundial de mulheres notáveis. Porto: Lello e Irmão, 1967, p. 966.

SCHUMAHER, Schuma \& BRAZIL, Érico Vital. Dicionário mulheres do Brasil. Rio de Janeiro: Zahar, 2000, p. 141.

SILVA, Marcelo Medeiros da. Carolina Nabuco: notas biobibliográficas. In: ARRUDA, Aline Alves et al. A escritura no feminino: aproximaçóes. Florianópolis: Mulheres, 2011, p. 41-50.

STRAUMANN, Heinrich. A literatura norte-americana no século XX. Rio de Janeiro: Editora Revista Branca, 1997.

THORP, Willard. Literatura americana no século XX. Trad. Luzia Machado da Costa. Rio de Janeiro: Lidador, 1965. 
Universidade Federal de Santa Catarina | www.periodicos.ufsc.br

\section{Carolina Nabuco: a lady in our literature}

Abstract: In this article it is commented the work of Carolina Nabuco, focusing especially on the book Retrato dos Estados Unidos à luz de sua literatura.

Keywords: Woman and literature. Carolina Nabuco. North American literature.

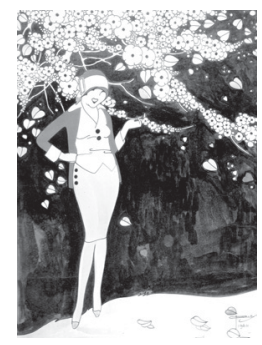

